\title{
An Approach Based on Advanced Manufacturing for Replacement Parts in Equipment Maintenance Context
}

\author{
Renan Andreassa NOVAKI ${ }^{\mathrm{a}}$, Athon F. C. S. de M. LEITE ${ }^{\mathrm{b}}$, Anderson L. SEJKA ${ }^{\mathrm{b}}$, \\ Osiris CANCIGLIERI Junior ${ }^{\mathrm{b}}$ \\ ${ }^{a}$ Lato Sensu Graduate Program in Engineering and Management in Industry 4.0, \\ Pontifical Catholic University of Paraná, Curitiba - Paraná, Brazil \\ ${ }^{b}$ Industrial and Systems Engineering graduate Program (PPGEPS) - Pontifical \\ Catholic University of Paraná, Curitiba - Paraná, Brazil
}

\begin{abstract}
Currently, in the context of equipment maintenance, new techniques for replacing parts and components are being discussed in order to ensure better performance. Seeking to optimize this process, this research proposes the development of a conceptual model that should work as methodology for the manufacture of replacement parts using the tools and concepts of Advanced Manufacturing. The research uses a methodology that excels in pre-processing information before modelling. First, a bibliographic research was carried out to obtain knowledge about Advanced Manufacturing in Industry 4.0, with emphasis on the domains of Additive Manufacturing, with a focus on testing by software. The method consists of the previous Project Feasibility Analysis, the Metrology fundamentals for data collection, until the manufacture of the part to be replaced. According to the analyses provided in this study, the results obtained meet the proposed criteria, in order to certify the quality of manufactured parts and making them feasible in terms of time and values. The research demonstrated an alternative to the traditional models of the maintenance process, using new techniques based on the Advanced Manufacturing models.
\end{abstract}

Keywords. Advanced Manufacturing; Pre-processing information; Industry 4.0.

\section{Introduction}

Increased productivity, time optimization and cost reduction are some of the pillars that companies are looking for currently, and within this context, a key point that guarantees the performance of machines and equipment, is maintenance, with the objective of maintaining the availability and eliminate defects that directly interfere with product quality. Thus, the replacement of damaged parts becomes a significant element in terms of corrective maintenance, based on the time of use or the physical condition of the part.

Many companies choose to purchase the parts to be replaced with the best applicability and quality in mind, ensuring the smooth operation of their equipment. This scenario results in high costs, due to the price of parts and the other taxes imposed on the importation of products and transport, as well as the estimated time for delivery, due to manufacturing and displacement until the replacement of the part in the field, requiring advanced planning, which is not possible in urgent cases, causing the machine to be unavailable for production due to the lack of the part immediately. The shorter the waiting time, the higher the service level of the supply chain [1]. 
This research focuses on optimizing the process of replacing parts for maintenance, ensuring the quality and applicability necessary for the proper functioning of machines and equipment.

The transdisciplinary nature of this study integrates the scientific and technical knowledge of manufacturing and the elements that govern the maintenance of equipment, developing a unified method on the different fronts of knowledge and science. As shown in figure 1, within the context of product development, Digital Manufacturing and Additive Manufacturing offer new standards, which can be adopted for such circumstances, featuring better flexibility in the corrective parts maintenance process, which has developed a method based on the foundations of Metrology, in which preprocessing of information stands out before modeling, helping in reducing costs in later phases and, as stated in literature [2], increasing productivity by producing better with less resources.

\section{Materials and Methods}

This research proposes, in a systemic way, the development of a method that structures the manufacturing of replacement parts in the scenario of Advanced Manufacturing. This study has an applied nature and a qualitative character [3]. As a conceptual basis, knowledge was obtained through a bibliographic study on two fronts: Additive Manufacturing and its manufacturing concepts, and Digital Manufacturing, with a focus on current structured methods.

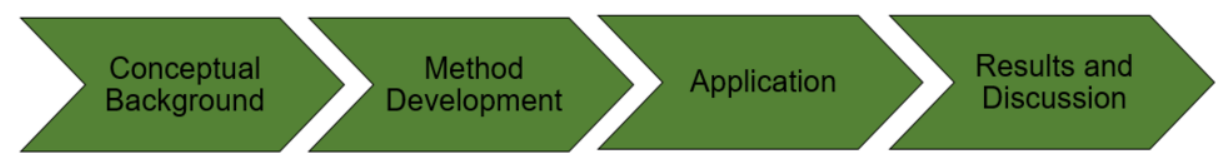

Figure 1. Methodological Procedures.

In order to obtain a solid base on those of advanced techniques in relation to manufacturing, the Conceptual Background addresses a qualitative review on Digital Manufacturing methods and Additive manufacturing methods.

The Method Development consists on developing a method with an emphasis on information pre-processing, using the fundamentals of preventive and corrective maintenance, as well as the fundamentals of Metrology in an Advanced Manufacturing scenario.

The Application of this study will be based on an experimental case, applied to a mechatronic equipment present in a Brazilian Pulp and Paper industry, aiming to optimize the Corrective Maintenance process. The Results and Discussion integrates the analyzes carried out in this study, in order to demonstrate an alternative means for replacing Maintenance parts.

\section{Conceptual Background}

The conceptual background revolves in a qualitative literature review conducted in the online scientific portal of the Brazilian Coordination for Improvement of Higher education Personnel (CAPES), which is an aggregator of more six-hundred scientific 
bases (including Springer, Scopus, IEEE, and others). Researched themes were Digital Manufacturing Application Methods and Additive Manufacturing.

\subsection{Digital Manufacturing application methods}

According to literature, some of the found methods of application for Digital Manufaturing of products were analysed and organised in a schema which demonstrates their step-by-step approach. Figure 2 depicts the analysed methods.

\begin{tabular}{|c|c|c|c|c|c|c|}
\hline Volpato et al. & $\underset{\rightarrow}{\mathrm{CAD}}$ & $\underset{\rightarrow}{\text { CAM }}$ & $\underset{\rightarrow}{\mathrm{STL}}$ & $\begin{array}{l}\text { Obtaining the } \\
\text { Model -> }\end{array}$ & $\begin{array}{c}\text { Manufacturing } \\
\rightarrow>\end{array}$ & $\begin{array}{l}\text { Post- } \\
\text { Processing }\end{array}$ \\
\hline Rodriguez et al. & $\underset{->}{C A D}$ & $\begin{array}{c}\text { CAM/CAPP } \\
\rightarrow\end{array}$ & $\underset{->}{\mathrm{STL}}$ & $\begin{array}{c}\text { File Slicing } \\
->\end{array}$ & $\begin{array}{c}\text { Manufacturing } \\
->\end{array}$ & Finishing \\
\hline Cunico et al. & $\underset{\rightarrow}{\mathrm{CAD}}$ & $\underset{\rightarrow}{\mathrm{STL}}$ & & $\underset{\rightarrow}{\text { File Slicing }}$ & $\begin{array}{c}\text { Post-Processing } \\
\rightarrow\end{array}$ & Finishing \\
\hline Canciglieri et al. & $\begin{array}{l}\text { Pre-Processing } \\
\text { Information -> }\end{array}$ & $\underset{\rightarrow}{\mathrm{CAD}}$ & $\underset{\rightarrow}{\mathrm{CAE}}$ & $\underset{\rightarrow}{\text { CAM }}$ & $\begin{array}{c}\text { Manufacturing } \\
\rightarrow>\end{array}$ & $\begin{array}{l}\text { Post- } \\
\text { Processing }\end{array}$ \\
\hline
\end{tabular}

Figure 2. Digital Manufacturing application methods

As seen in Volpato [4], the CAM complements the stage of digital CAD development, with the orientations of the part and support structures, proceeding to direct manufacturing and post-processing in layers, defining the stage of finishing the part.

In Rodriguez et al. [5], The toolpaths for each layer in the CAM step and a CAPP post-processing, and sequentially, the fabrication of the part can be inspected to determine dimensional and/or geometric errors in the slicing step [6].

In contrast, in Cunico [7] five steps related to manufacturing processing, divided into CAD modeling, conversion into STL machine language, layers of processing; layerby-layer construction; post-processing and finishing.

As seen in Canciglieri et al. [8], the method started by obtaining preliminary information from clients, characterised as patients in this study, applying the analysis in a Dental Product Case. Subsequently, the product was designed in CAD, and carried out tests in CAE software, as well as the planning of CAM process. When manufacturing, there is a need for post-processing of the printed part.

The method served as the basis for this study [8], given the opportunity to expand the method and go deeper in Pre-Processing, migrating to the manufacture of spare parts in an environment of maintenance of equipment and machines, with emphasis on the survey information and prior feasibility analysis, which characterize this project

\subsection{Additive Manufacturing}

Three-dimensional printing represents, in a generalized way, several techniques to create an object starting from the project in software or radiographic data. Each type of 3D printing exemplifies materials of different requirements, costs and effectiveness [9][10]. To provide a more comprehensive view, Figure 3 demonstrates 3D printing methods taking into account in this research. 


\begin{tabular}{|c|c|c|c|c|c|}
\hline Types & Composition & Process & Advantages & Disadvantages & Costs \\
\hline SLA & Liquid Resin & UV Exposure & $\begin{array}{c}\text { High } \\
\text { Resolution }\end{array}$ & $\begin{array}{l}\text { Long Printing } \\
\text { Times }\end{array}$ & High Costs \\
\hline Clip & Liquid Resin & $\begin{array}{l}\text { Liquid Resin } \\
\text { Pool }\end{array}$ & $\begin{array}{c}\text { High } \\
\text { Resolution }\end{array}$ & $\begin{array}{l}\text { Long Printing } \\
\text { Times }\end{array}$ & High Costs \\
\hline MJP & Liquid Resin & Light Curing & $\begin{array}{c}\text { Low } \\
\text { Maintenance }\end{array}$ & Drops Materials & High Costs \\
\hline BJP & Powder Base & By Layers & $\begin{array}{l}\text { Small and } \\
\text { Silent }\end{array}$ & Post Processing & $\begin{array}{l}\text { Affordable } \\
\text { Costs }\end{array}$ \\
\hline SLS & $\begin{array}{l}\text { Binding } \\
\text { Substance }\end{array}$ & By Layers & Any Material & $\begin{array}{l}\text { Limited } \\
\text { Resolution }\end{array}$ & High Costs \\
\hline FDM & $\begin{array}{c}\text { Solid } \\
\text { Thermoplastic } \\
\text { Filament }\end{array}$ & By Layers & $\begin{array}{c}\text { Most } \\
\text { Common and } \\
\text { Accessible }\end{array}$ & Low Resolution & Low Costs \\
\hline
\end{tabular}

Figure 3. Additive Manufacturing Techniques. Adapted from Crafts et al. (2017)

In a comparison of all methods SLA is a polymerization method where the precursor layers of the liquid are sequentially exposed to ultraviolet (UV) light, and thus selectively solidified [11][12]. The Multijet process (MJP) is very similar to the process of a conventional printer, where the material and an agent are ejected from the head, the same way as an ink printer, which the name makes an analogy [13]. Folder jet printing (BJP) differs from the other methods above, in which a powder base is used with the binding substance. After drying, materials added to the powder and binder may include metals, glass and sand [9]. SLM or SLS is a powder bed melting process, in which selective regions of the powder particles are melted and fused by a high intensity laser energy source, layer by layer according to computer aided design (CAD) [6][14]. The liquid thermoplastic FDM material is deposited in ultrafine layers on a substrate. The material is heated one degree above its melting point so that it immediately solidifies after extrusion [15].

According to literature, the printing methods have different characteristics, resulting in a range of printing options for each required application. The approach of this study corresponds to the FDM method, in which it is characterized by the simplification of printing and common availability in the academic, business and social environment.

\subsection{D Printing in Maintenance}

The importance of maintenance for manufacturing systems leads to the creation of several maintenance goals, each of which is applicable to a specific manufacturing system [16].

According to Camargo et al. [17], the new technological revolution brings advantages for industrial maintenance, making it available in a shorter repair time and greater availability of machinery, given the savings in the purchase of preparation parts and ease in handling the 3D printer.

The technology has the ability to print from simple to more complex parts, so that they can replace part of the materials of original parts and meet the needs of the industry in terms of maintenance [18].

It is a relatively new field and could contribute to the expansion of development in this area, deepening the inclusion of these technologies in the development and implementation of maintenance activities and systems [19]. 


\section{Proposal}

This research is developed under the process of Corrective Maintenance of parts in mechatronic equipment, in which it is based on the analysis of the data and properties collected for purposes of comparison between the methods currently adopted in the companies.

The proposed method is a variation of the model "Conceptual proposal for an advanced manufacturing model with an emphasis on creating dental prosthesis prototypes in jaws" [8] adhered to the Manufacturing process, with emphasis on Preprocessing of information before modeling.

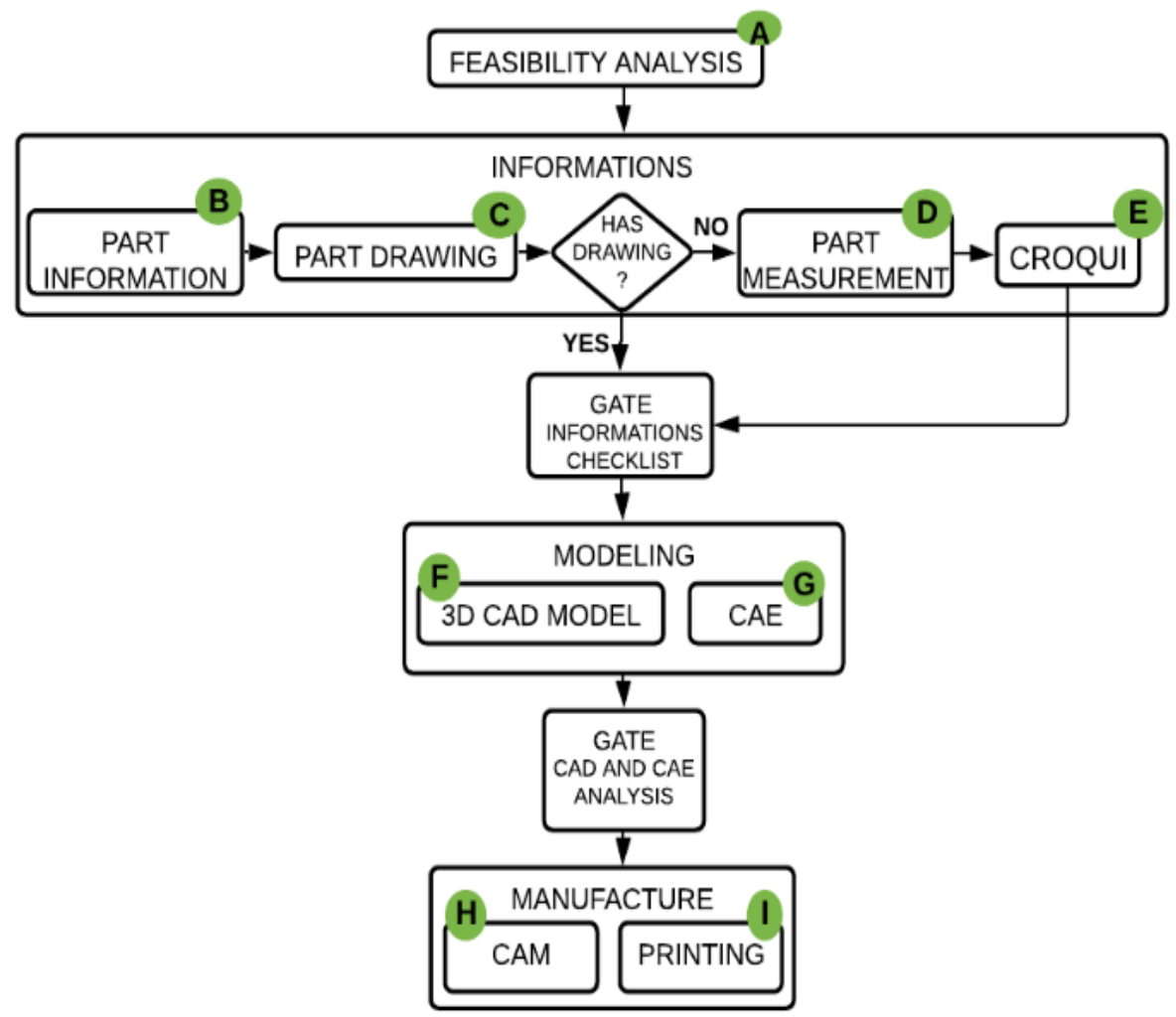

Figure 4. Proposed Method

Figure 4 describes the systemic method for the development of the project. The viability of the part consists of the analysis of data and information about the process of replacing parts in the current concept of the company. The analysis foresees the accounting survey of the acquisition of replacement parts, such as transport values, imports, insurance, taxes and material value. The costs raised in this analysis must be higher than the cost of manufacturing by additive manufacturing, to justify the application of this method, in loco to the company (Detail A of Figure 4).

The data collection covers technical characteristics present in the operation and maintenance manuals of the equipment, such as geometric diagrams, technical drawings and the work mode of the part. 
According to the performance, the part undergoes constant efforts in its structure, and this factor generates deformations and wear with the time of use. The analysis corresponds to the way in which the part acts on the equipment, such as: direct contact of the part with the equipment structures, mechanical efforts, equipment under pneumatic or hydraulic pressure, performance under high temperatures, humid or submerged environments, among others (Detail B of Figure 4).

The technical drawing provides the necessary information for the understanding and construction of the part, thus facilitating the transposition of the information to a CAD software (Detail C of Figure 4).

In the absence of a technical drawing, this study values the techniques and foundations of Metrology to perform the necessary measurements of the piece, considering all faces and angles, which are fundamental for digital development (Detail D of Figure 4).

After collecting the measurements of the piece, the representation of the sketch is given by the practice of hand drawing, and according to the information represented, that the virtual model will be definitively molded in the modeling stage (Detail E of Figure 4). For the realization of the virtual model, a CAD software will be used, due to the ease of operation and interaction with the user. Among other characteristics, the models clearly demonstrate the architecture of the piece, being able to edit the project at any time during its projection (Detail F of Figure 4).

After the three-dimensional development, the analysis by the CAE system consists of testing the physical properties of the material, thus certifying the quality and applicability of the piece. With the result showing to be satisfactory, the stage proceeds to the manufacture of the part (Detail G of Figure 4). The CAM phase addresses the details of the manufacturing process, assisting the supervisory of the printing method in relation to the tool, material quantity, final touch and the time established according to the design of the part (Detail H of Figure 4).

The final step consists of printing the piece, based on the settings and parameters established during the study in a methodological manner, according to the printing characteristic (Detail I of Figure 4).

\section{Application}

The application of the study is characterized as a pilot study (preliminary application), which is directed to a Mechatronic equipment, present in a Brazilian company of Pulp and Paper. The analysis focuses on a pulley, which acts mechanically as a guide under a seal of internal sealing of the equipment, making it possible to analyze and develop the method covered in this research. Currently, the company has eight key small components of high impact in the manufacturingin process in a similar scenario as the selected part, in which the cost of purchasing and replacing original parts generates higher costs for the company. Such parts correspond to rollers, cable and hose carriers, equipment protections, specific tools, and obsolete replacement parts.

The focus of application is on the corrective maintenance process of the studied company. Corrective maintenance in the company occurs when the physical condition of the part in the field has deteriorated and use time has been overdue. The former occurs at random times during production and the latter is based on manufacturer's recommendation. In the fisrt scenario, there is tardiness in the maintenance response if there are more than two stops in a three-week period (average lead-time to receive 
replacement parts from manufacturer), resulting in the unavailability of the machine and generating consequences to the entire business chain, from spending on raw materials and wasted energy to delays in delivering the final product to customers. In another aspect, ordering extra replacement parts from the manufacturer imply in higher costs and aproximately doubles the storage cost for the parts in the company. Thus, the lead-time of arrival of replacement parts ends up generating costs and affects the whole operation.

The data obtained were taken from the company's software and contact with suppliers of the part. The cost per unit of the pulley is currently $\$ 17.00$. Based on market research, the cost per $\mathrm{kg}$ of a material for the Additive Manufacturing method is $\$ 15.00$, which considers the possible multiple manufacture of parts with only $1 \mathrm{~kg}$ offered in the national market.

The material of the pulley was possible to obtain under consultation to the manual and using the visual method, certifying the use of Polyacetal to manufacture the part. For the purpose of comparison and applicability, the properties of the Acrylonitrile Butadiene Styrene (ABS) material, used for manufacturing under the Additive Manufacturing method, were analyzed together. The collections of material information are represented in Table 1, based on sources [20] [21] [22]:

\begin{tabular}{|l|c|c|}
\hline \multicolumn{1}{|c|}{ Properties } & Polyacetal & ABS \\
\hline Tensile Strength $(\mathrm{MPa})$ & 70 & 32 \\
\hline Toughness $(\mathrm{MPa})$ & 170 & 74 \\
\hline Short-Term Temperature $\left({ }^{\circ} \mathrm{C}\right)$ & 110 & 75 \\
\hline Long-Lasting Temperature $\left({ }^{\circ} \mathrm{C}\right)$ & 150 & 100 \\
\hline
\end{tabular}

Table 1: Material Information

The mechanical and thermal properties of both materials, demonstrate a difference in relation to some parameters, highlighting a good performance in relation to temperature resistance. The application equipment has an average internal temperature of $45^{\circ} \mathrm{C}$, which results in the good applicability of the ABS material, whose long-term temperature is $100^{\circ} \mathrm{C}$. The higher the values of properties, the better the material's strength and applicability.

The design and measurements of the piece were obtained manually, using measurement instruments according to the concepts of Metrology, considering all the faces and edges of the piece for the previous elaboration of a sketch.

According to the Sketch, the modeling is performed with the aid of a CAD Software, as described in Detail A of Figure 5, in which later its properties are tested and certified according to the CAE Software. The modeling and simulation results in the CAE stage represented graphically the following analyzes in relation to their natural state, using the properties of the ABS material to carry out the simulations.
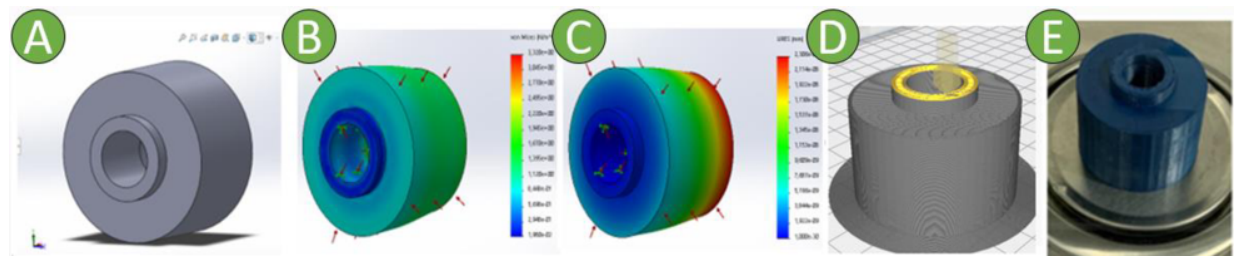

Figure 5: Modelling and Manufacturing

For the representation of Von Mises Stress simulation, we had a point where there was greater criticality, with the stresses of $4,161 \times 10^{\wedge} 02 \mathrm{~N} / \mathrm{m}^{\wedge} 2$. In general, the points 
at which the pulley is exposed to constant forces, present a result between $3.572 \times 10^{\wedge} 02$ and $1.807 \times 10^{\wedge} 02$, with no wear or deformation depending on the applied actions, as described in Detail B of Figure 5.

The static displacement analysis, described in Detail $\mathrm{C}$ of Figure 5 obtained a displaced sample in the fixation region, where it presents a value of $2.306 \times 10^{\wedge}-08 \mathrm{~mm}$. The distributed result obtains values between $1,000 \times 10^{\wedge}-30$ to $1,730 \times 10^{\wedge}-08$, which does not imply significantly to the point of preventing the manufacture and use of the part with the selected material, due to the low impact on the performance of the equipment. The levels presented in the simulation demonstrate the resulting effect on the piece, in which the criterion of indications is adopted to guarantee the quality of the material in relation to its application. The results obtained in the analysis and information gathering certify the quality and applicability of the project, where the impact remains under the lowest levels in the simulation, which is adopted as an acceptable criterion, thus destining the manufacture of the part.

Detail D of Figure 5 represents the CAM stage and Detail E of Figure 5 the threedimensional impression of the piece. According to the related works of this research, the FDM mode has been used to manufacture the part, according to the character of the 3D printer.

In this context, the application described is characterized as a pilot study of the method in a real application, in which it analyzes the results in an empirical way, being able to be applied in the other components in similar scenarios. Thus, in the scope of corrective maintenance, the application of the method addressed in this study can be extended to other processes in maintenance or manufacturing, involving different equipment and technical areas, reducing time and cost, ensuring the necessary quality for the proper functioning of the equipment.

\section{Results and Discussion}

The proposed method brings points in which the analysis allows its applicability, with emphasis on the questions of cost and time, describing the comparison between the current processes adopted by the company in relation to Corrective maintenance in equipment.

The pre-processing of information allowed a general analysis of the environment and the functionality in which the part and the equipment are located, aiming at the optimization of the process according to its feasibility.

In question, the company adopts a flow for the acquisition of spare parts, which describes itself from the need to check the condition of the part in the field, to the request for direct purchase with suppliers of the part or equipment. The estimated time after the purchase of the part takes the equivalent of 5 to 7 working days for the delivery of the product.

\begin{tabular}{|l|c|c|}
\hline \multicolumn{1}{|c|}{ Variable } & Before & After \\
\hline Time & 5 to 7 days & 5 to 6 hours \\
\hline Costs & 17 \$ per part & 0.30 \$ per part \\
\hline Amount of Material & $60 \mathrm{~g}$ & $20 \mathrm{~g}$ \\
\hline
\end{tabular}

Table 2: Before and After Comparison

According to the application described in this study, the Additive Manufacturing method corresponds to an $86 \%$ reduction in delivery time, due to the fact that the manufacturing lasts an average of 5 to 6 hours, according to the expected quality. 
Based on the analysis of the methods covered in the literature, according to the availability at the place of application of this study, the FDM printing method met the quality requirements.

Under the availability of material on the market, the sale of raw material to a 3D printer corresponds to $1 \mathrm{~kg}$ of material, in which multiple pieces can be manufactured, which use an average of $20 \mathrm{~g}$ of material for each pulley, resulting in 50 units costing $\$ 0,30$ cents a Dollar each. Production possibilities, and according to the analyzes and simulations by Digital Manufacturing, the material used for the manufacture of the pulley keeps the minimum requirements to guarantee a useful life time for the equipment.

In terms of materials, the comparison between the pieces is a $40 \mathrm{~g}$ reduction using the Additive Manufacturing method, considering the absence of material loss in the manufacture and the quality guarantee using the ABS material for the manufacture of the piece, which aims at this study.

The modeling based on the principles of Advanced Manufacturing resulted in the guarantee that other materials can be adopted in the manufacture of the parts that will be replaced, maintaining the quality and applicability necessary for the proper functioning of the equipment.

As a result, the application of this method becomes feasible in order to manufacture the part in loco the company in which this study was developed, allowing the reduction of waiting time for the acquired part and the high cost due to the external purchase of the part, which requires advance planning.

\section{Conclusion}

In view of the preventive and corrective Maintenance scenario, this study proposed a systemic method in which it addresses the fundamentals of Digital Manufacturing with an emphasis on Additive Manufacturing, based on the pre-processing of information under Metrology principles.

The study showed improvement in the replacement parts scenario, addressing the requirements of time of acquisition and availability, and the cost of purchasing the necessary part, thus optimizing the process of replacing damaged parts. Therefore, it is possible to apply the method addressed in this case in face of other corrective and preventive Maintenance processes, as well as an alternative method for manufacturing parts for replacement.

As a future proposal for the application of the method described in this study, other processes in maintenance or manufacturing are suggested, involving different equipment and parts, covering various technical areas such as mechanics, electrical, electronics, among others. The results could improve the method and its limitations for optimizations in preventive and predictive analyzes in equipment, as well as providing a study related to Prescriptive Maintenance, intended for Industry 4.0.

\section{Acknowledgement}

Authors would like to acknowledge the Lato Sensu Graduate Program in Engineering and Management of Industry 4.0 and the Industrial and Systems Engineering Graduate Program of the Pontifical Catholic University of Paraná (PUCPR) for the structure and support, and the company where this study was carried out. 


\section{References}

[1] D.J. Bowersox, D.J. Closs, M.B. Cooper, J. C. Bowersox, Gestão Logística da Cadeia de Suprimentos. 4. ed. Amgh, Porto Alegre, 2013.

[2] V.F. Campos, TQC-Controle Da Qualidade Total - No Estilo Japonês. 9. ed. Falconi, Belo Horizonte, 2013.

[3] D. E. Gray, Pesquisa no mundo real. Editora Penso, Porto Alegre, 2012.

[4] N. Volpato, Manufatura aditiva: tecnologias e aplicações da impressão, 3d. Blucher, São Paulo, 2017.

[5] E. Rodriguez, R. Bonnard, A. Álvares, Avances en el desarrollo de un sistema de manufactura aditiva basado en STEPNC. Revista Produção e Desenvolvimento, 2018, Vol.4, No. 1, pp. 39-53. DOI: https://doi.org/10.32358/rpd.2018.v4.310.

[6] M. Gupta, 3D Printing of Metals. Mdpi, Singapore, 2017. https://doi.org/10.3390/books978-3-03842-592-2.

[7] M.W.M. Cunico, Impressoras 3D: o novo meio produtivo. Concep3D Pesquisas Científicas Ltda, Curitiba, 2015.

[8] M.B. Canciglieri, A.F.C.S. Leite, A.L. Szejka, O. Canciglieri júnior, An approach for dental prosthesis design and manufacturing through rapid manufacturing technologies. International Journal of Computer Integrated Manufacturing. 2019, pp. 832-847.

[9] T.D. Crafts, S.E. Ellsperman, T.J. Wannemuehler, T.D. Bellicchi, T.Z. Shipchandler, A.V. Mantravadi, ThreeDimensional Printing and Its Applications in Otorhinolaryngology: head and neck surgery. Sage, Indianapolis, 2017.

[10] I. Gibson, D.W. Rosen, B. Stucker, Additive Manufacturing Technologies: rapid prototyping to direct digital manufacturing. Springer, New York, 2010.

[11] A. Biahmou et al., Towards agile enterprise rights management in engineering collaboration, International Journal of Agile Systems and Management, 2016, Vol. 9(4), pp. 302-325.

[12] Z. Weng, Y. Zhou, W. Lin, T. Senthil, L. Wu, Structure-property relationship of nano enhanced stereolithography resin for desktop SLA 3D printer. Elsevier, Beijing, 2016.

[13] V. CABReIRA, Avaliação Dos Parâmetros De Processamento Em Impresão $3 d$ Nas Propriedades Do Poliácido Lático. 2018. 104 f. Monografia (Especialização) - Curso de Programa de Pós Graduação em Engenharia de M, Escola de Engenharia, Universidade Federal do Rio Grande do Sul, Porto Alegre, 2018.

[14] S. Sun, B.R. Ramachandran, C.D. Wick, Solid, liquid, and interfacial properties of TiAl alloys: : parameterization of a new modified embedded atom method model. Journal Of Physics: Condensed Matter, 2017, pp. 1-12.

[15] T.s. Srivatsan, T.s. Sudarshan, Additive Manufacturing: innovations, advances, and applications. CRC Press Taylor \& Francis Group, Boca Raton, 2016.

[16] A. Shahin, H. Shirouyehzad, E. Pourjavad, Optimum maintenance strategy: A case study in the mining industry. International Journal of Services and Operations Management, 2012, Vol. 12, No. 3, pp. 368-386.

[17] G.R.R. Camargo, P.A.G. Barbosa, F.d.A Santos, 3D Printing in Industrial Maintenance and Cost Reduction. 2021. 26 f. Curso de Tecnologia em Gestão Financeira, Faculdade de Tecnologia do Estado de São Paulo, Osasco, São Pulo, 2021.

[18] G.A.A. Lopes, E.V.C. Galdamez, Additive Manufacturing for the Production of Maintenance Parts. 2018. 39 f. Curso de Engenharia de Produção, Centro de Tecnologia, Universidade Estadual de Maringá, Maringá - Paraná, Brazil, 2018.

[19] D.R.T. Velázquez, A.L. Helleno, C.R.C. Lima, L.H. Mastrapa, Implications of Hybrid Manufacturing Technologies on Parts Repair and Remanufacturing Processes in Maintenance Context: A Systematic Review. 2020. $21 \mathrm{f}$. Curso de Engenharia de Produção, Universidade Católica do Rio de Janeiro, Piracicaba, Brazil, 2020.

[20] B.d.S. Souza, Replacement of polyacetal for polypropylene in the clothespin structure. 2018. $57 \mathrm{f}$. TCC (Graduação) Curso de Production Engineering, Santo Amaro University, São Paulo, 2018.

[21] M. Vasina, K. Monkova, P.P. Monka, D. Kozak, J. Tkac, Study of the Sound Absorption Properties of 3D-Printed Open-Porous ABS Material Structures, Polymers, 2020, Vol. 12, no. 5: 1062.

[22] FISQP - FICHA DE INFORMAÇÃO DE SEGURANÇA PARA PRODUTOS QUÍMICOS. NBR-14.725: TECARAN ABS grey - Semiacabados. 1 ed. Ensiger, São Leopoldo, 2020. 